\title{
Retrospective Analysis of Patients with Genitourinary Fistula
}

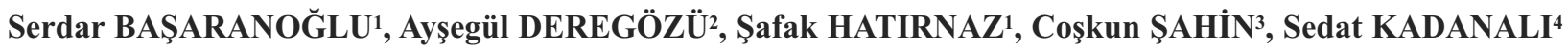 \\ Istanbul, Turkey
}

\begin{abstract}
OBJECTIVE: To present the outcomes of patients treated at a tertiary center for a diagnosis of genitourinary fistula secondary to gynecological and obstetric etiologies.
\end{abstract}

STUDY DESIGN: In this retrospective study, analysis was made of 18 patients with a diagnosis of genitourinary fistula in a tertiary center between January 2006 and June 2016. Patient data were taken from the archives and patient histories. A record was made of examinations, diagnostic methods such as cystoscopy and fistulography and appropriate medical treatments, demographic data, intraoperative and post-operative complications, duration of hospital stay, surgical operations and types, diameter and location of fistulas.

RESULTS: Of the 18 cases, 14 were secondary to obstetric trauma. In 10 of these 14 cases, fistula had developed after difficult vaginal delivery and in four cases, after caesarean section. Four of the 18 cases were secondary to gynecological surgeries, namely hysterectomy and cystocele repairs. Vesicovaginal fistulas were repaired transvaginally while vesicouterine fistulas and bilateral ureterovaginal fistulas were repaired transabdominally. The mean hospital stay was $3.8 \pm 1.5$ days ( $2-7$ days). Patients were followed up closely in the first 3 months and recurrence developed in only one case.

CONCLUSION: Fistulas secondary to gynecological procedures are uncommon while fistulas secondary to inadequate perineal care, insufficient labor monitoring and difficulties in vaginal delivery techniques are more prevalent in Turkey. Thorough evaluation, using all diagnostic tools for complete diagnosis, understanding the pathophysiology and choosing the best surgical procedure are mandatory to obtain good outcomes after the surgical

Keywords: Genitourinary fistula, Vesicovaginal fistula, Ureterovaginal fistula, Transvaginal repair

Gynecol Obstet Reprod Med 2017;23(3):148-152

\section{Introduction}

Fistula is an epithelized, extra-anatomic tract between organs and/or body surface. These tracts between genital organs and the urinary tract are called genitourinary fistulas (1). Genitourinary fistulas result in continuous or intermittent urinary incontinence. This is a significant public health issue

\footnotetext{
${ }^{I}$ Bilge Hospital Department of Obstetrics and Gynecology, Istanbul

${ }^{2}$ Bahçelievler State Hospital Obstetrics and Gynecology, Istanbul

${ }^{3}$ Private Office Urology Center, Istanbul

${ }^{4}$ Private Office Obstetrics and Gynecology Center, Istanbul

Address of Correspondence: Serdar Başaranoğlu Bilge Hospital Department of Obstetrics and Gynecology, Istanbul, Turkey drsbasaran@gmail.com.tr

Submitted for Publication: 11.10 .2016 Accepted for Publication:

16.03.2017
}

\begin{tabular}{|c|c|}
\hline & Access this article online \\
\hline $\begin{array}{c}\text { Quick Response Code: } \\
\text { 口uㅏ. }\end{array}$ & Website: www.gorm.com.tr \\
\cline { 2 - 3 } & DOI:10.201613/GORM.2016.637 \\
\hline
\end{tabular}

How to cite this article: Basaranoğlu S. Deregözü A. Hatırnaz S. Sahin C. Kadanall S. Retrospective Analysis of Patients with Genitourinary Fistula. Gynecol Obstet Reprod Med 2017;23(3):148-152 with negative physical, emotional and social impacts on individuals, which may eventually lead to loss of self-confidence, stress, inadequate libido and social dissociation $(2,3)$. Genitourinary fistula (GUF) is more prevalent in countries with limited access to healthcare. The underlying factors have been reported as obstetric trauma, prolonged labor and female circumcision in some African countries (4). In developed countries, the precipitating factors are pelvic surgery, sling operations (transobturator tape-TOT, transvaginal tape-TVT, and mini sling), cancer surgery and history of radiotherapy (5-7).

The incidence varies depending on the socioeconomic and cultural level of the country and the underlying etiologies. Fistula rates secondary to obstetric operations have been reported as $0.3-2 \%$ in developed countries and as $65 \%-96 \%$ in underdeveloped countries (8). According to the World Health Organization (WHO) 2006 classification, fistulas are categorized into two groups as simple and complex. Vesicovaginal fistulas (VVF) seen in various locations are the most frequent type of GUF (9). The estimated number of patients with untreated VVF secondary to obstetric causes is more than 2 million globally and an estimated $100.000-150.000$ new patients are added to that number annually (10). The aim of treatment is to eliminate urinary incontinence and to establish normal 
genito-urinary functions. Fistula tract repair may be performed abdominally, vaginally, laparoscopically or by using robotic surgery. Currently, the vaginal approach is the most preferred method for GUF treatment, although each method has its own advantages and disadvantages.

The aim of this study was to present the results of patients treated surgically for a diagnosis of GUF in the light of current literature.

\section{Material and Method}

In this retrospective study, an analysis was made of 18 patients treated in a tertiary center for a diagnosis of GUF between January 2006 and June 2016. Clinical and demographic data from the history at admission and findings about performed surgical operations were retrieved from patient charts in the archives and electronic records. Patient data such as age, gravida, parity, abortion, number of living children, history of systemic diseases (Diabetes mellitus-DM, hypertension-HT, asthma, smoking), previous obstetric (vaginal delivery, caesarean section), gynecological (hysterectomy, operations for malignant gynecological tumors), urogynecological (cystocele, rectocele, vaginal hysterectomy) operations, incontinence surgery (sling and mesh operations), referral complaints, and time from onset of the symptoms were recorded. All patients were referred to the Urology Department after gynecological examination. The diagnosis of GUF was confirmed by the patient history, gynecological examination and radiological examinations (fistulography, cystoscopy, hysterosalpingography). Genitourinary fistula tracts were determined by methylene blue. Intraoperative and post-operative complications, duration of hospital stay and surgical operations performed were recorded. Surgery was performed on all patients by an urologist. The surgical procedures are described below.

\section{Vesicovaginal fistulas}

An intact vagina-bladder junction was detected after the determination of the fistula tract. The fistula was excised after adequately exposure with a midline incision at the posterior bladder neck. For primary repair of the resultant defect, absorbable sutures were used (preferably 2.0 vicryl) and the layers were sutured on longitudinal and sagittal plane. The bladder was filled with 150cc saline to detect any leakage. A vaginal flap was used for closure of the defect when required. A Foley catheter was inserted in the postoperative period and bladder distension was prevented for 14 days. The patients were hydrated until hematuria coming through the catheter ceased. The catheter was changed if it became blocked. Prophylactic antimicrobial therapy was administered to every patient.

\section{Vesicouterine fistulas}

Entry to the abdomen was made with a Pfannenstiel incision, and then the fistula tract between the uterus and the bladder was detected by blunt and sharp dissection. The bladder dome was incised. The tissues were dissected using a clamp and the fistula tract was excised up to the opening of the fistula. The resultant uterine defect was repaired with $3 / 0$ vicryl. Double layer closure of the resultant bladder defect was made using 3/0 vicryl. $200 \mathrm{cc}$ saline was applied from the urethra and leakage was controlled. The operation was finished according to the abdomen anatomy. A 20 f Foley catheter was inserted in the postoperative period. Foley and was kept in place for 7-14 days. No complications developed related to longterm catheterization in any patient.

\section{Results}

A total of 18 patients with a diagnosis of GUF were treated concordantly in the Obstetrics \& Gynecology and Urology Clinics during the study period. In the demographic characteristics of the patients, mean age was determined as $35.9 \pm 11.5$ years, gravida was $2.9 \pm 1.3$, parity was $2.5 \pm 1.0$, the mean number of abortions was $0.4 \pm 0.5$ and the number of living children was $2.5 \pm 1.0$. The mean time from the onset of symptoms to the referral to our clinic was 7.1 \pm 4.6 months (range, 2-18 months). The patients were divided into a menopausal age group and reproductive age group. In the menopausal age group, one patient had DM and two patients had hypertension. In the reproductive age group, three patients were smokers and one patient was undergoing chemotherapy for colon cancer. Intraoperative measurements showed that the mean fistula diameter was $9.2 \pm 4.6 \mathrm{~mm}$ (range, 6-15 mm). Vesicovaginal fistulas (VVF) were detected in 15 cases, of which 10 had a history of difficult vaginal deliveries and two cases had a history of cesarean hysterectomy due to uterine atony. The cases, which developed secondary to gynecological surgeries, were distributed as follows: one after total abdominal hysterectomy (TAH), one with TAH as an adjunct to colon cancer treatment with chemotherapy support after surgery and one case secondary to cystorectocele $(\mathrm{CRC})$ repair. Ureterovaginal fistula, a rare form of fistula, was recognized during a routine postoperative visit on the $14^{\text {th }}$ day after cervical cancer surgery by the visualization of urine leakage from the vagina. In two cases operated on for vesicouterine fistulas (VVF) this complication was identified after caesarean section. The major complaints of the patients were secondary amenorrhea and blood in the urine (hematuria). In the patient with ureterovaginal fistula, the fistula tract was on the interureteric bridge. For a sound fistula repair, alteration of the ureter tract was required and the fistula tract was repaired with bilateral ureteroneocystostomy (UNS). There were no intraoperative complications and transfusion was required in only one patient. The mean hospitalization was 3.8 \pm 1.5 days (range, 2-7 days). In the first 3-month follow up, recurrence was observed in one patient in the secondary group.

\section{Discussion}

Surgical interventions performed in Obstetrics \& Gynecology practice increase urinary tract complications due 
to close embryological and anatomical proximity (11). The etiology of fistulas includes obstetric trauma, gynecological operations (particularly hysterectomy), chronic inflammatory diseases, radiotherapy, genital cancers, pelvic surgery, prolonged urinary catheterization, colporrhaphy anterior, incontinence surgery (with slings and mesh), urethral trauma, infection, trauma and foreign bodies $(12,13)$. Vesicovaginal fistulas are the most frequent acquired type followed by less frequent forms such as vesicouterine and ureterovaginal fistulas. In developed countries, fistulas secondary to pelvic surgery, cancer surgery and radiotherapy are more prevalent and fistulas secondary to obstetric etiology are rare. In underdeveloped countries or in countries with poor access to healthcare, fistulas are usually secondary to obstetric trauma or prolonged labor $(5,14)$. When obstetric etiology is assessed further, caesarean section, the use of vacuum of forceps, episiotomy and prolonged labor are the most frequent obstetric causes.

Data from the Mayo and Kettering clinics have shown that $82 \%-91 \%$ of VVF were secondary to gynecological operations and $4 \%-5 \%$ were secondary to radiotherapy and $5 \%$ were secondary to obstetric trauma, anterior colporrhaphy and catheter use (15). In a large series, Lee et al. reviewed 303 patients and reported that $82 \%$ of GUF were due to gynecological operations, $8 \%$ to obstetric interventions, $6 \%$ to radiotherapy and $4 \%$ to trauma (16). From a review of studies conducted in Turkey, there can be seen to be a variety of fistulas secondary to gynecological causes, which were reported at $77.8 \%$ by Çiftçi et al., $50 \%$ by Kaplan et al. and $90.9 \%$ by Karateke et al. (17-19). In the current study, VVF was determined in 15 patients, 12 $(80 \%)$ of which were secondary to obstetric causes and 3 $(20 \%)$ were secondary to gynecological causes.

Various studies in literature have reported the rate of bladder injury following hysterectomy as $0.05-8.3 \%(20-24)$. The rate of fistula secondary to hysterectomy varies depending on the hysterectomy type. Following radical hysterectomy, the fistula rate has been reported as $1 \%-4 \%$ and after subtotal hysterectomy as $13.7 / 100.000(25,26)$. In the current study, VVF developed in two patients after caesarean section+TAH and ureterovaginal fistula developed in one patient who had undergone radical surgery for cervical cancer.

The formation of obstetric fistulas varies depending on the type of delivery. Prolonged labor is the main culprit in the formation of fistula after vaginal delivery. The main problem is hypoxia due to prolonged labor. In addition, the use of vacuum, forceps and episiotomy are considered risk factors. The fistula is usually located in the anterior vaginal wall and in the mid-vagina. In the current study, VVF developed in 10 patients after vaginal delivery and this was the most frequent $(10 / 15)$ cause of fistulas. Vesicovaginal fistulas were located in the vaginal anterior proximal section.

Fistulas developing after caesarean section may be located in various locations. Incisions to the inferior segment of the uterus are the most frequent cause of vesicouterine fistula development (27). Youssef first described vesicouterine fistulas in 1957 (28). Cyclic hematuria without incontinence and secondary amenorrhea are the classic symptoms of vesicouterine fistula (29). In addition to caesarean section, the use of vacuum during labor, vaginal delivery after caesarean section and the use of Intrauterine device (IUD) are considered as risk factors. Hysterosalpingography (HSG), cystography, cystoscopy, sonohysterography, and magnetic resonance imaging (MRI) can be used for the diagnosis of vesicouterine fistulas (30). Hysterosalpingography is the most commonly used radiological method for diagnosis (31). In the current study, methylene blue and cystoscopy were used for diagnosis, after which the operation decision was taken. Vesicouterine fistula was determined in two of the current study cases and both had a history of caesarean section. Increasing age and smoking are known to have a negative impact on fibroblast activity and decrease collagen production (32). These factors negatively affect tissue healing. In the current study, the mean age of the patients was $35.9 \pm 11.5$ years and only three patients reported tobacco use.

To recover normal genital and urinary functions by eliminating urine leakage are the main goals of fistula treatment. Transvaginal and transabdominal approaches are successfully applied as surgical techniques. The size and location of the fistula, epithelization of fistula tissue, the presence or absence of scar tissue and proximity to the ureteral orifice affect the success rate of surgery (33). Both techniques have their own advantages and disadvantages depending on the type of fistula. Currently, the transvaginal approach is the most frequently used technique in VVF repair. Currently more than $90 \%$ of fistulas developing secondary to obstetric causes, incontinence operations, iatrogenic causes, and mesh and sling operations are treated by the transvaginal approach (34). The abdominal approach is another method and has the advantages of the provision of the optimal surgical area, and opportunities facilitating the use of omental and peritoneal flap (35). In the current study, in 15 patients with VVF secondary to caesarean section+TAH, CRC repair and TAH fistulas were repaired transvaginally. Ureterovaginal and vesicouterine fistulas were treated transabdominally with no use of omental and peritoneal flaps.

Various opinions have been aired in literature about the timing of surgical intervention. Some authors have stated that repair should be applied as early as possible (1-3 months) after the primary injury, while others have stated that repair should be made later (after at least 3 months) $(36,37)$. The objective of treatment at a later stage is to wait for absorption of previous operation sutures and to be able to detect the fistula location more easily. In the current study, the time from onset of symptoms to referral to our clinics was mean 7.1 \pm 4.6 months (range, 2-18 months). The decision to operate was taken after the diagnosis of the patient was established. Fistula diameter of $>30 \mathrm{~mm}$ has been reported to decrease the success 
rate of the surgery (17). In the current study, the mean fistula diameter was $9.2 \pm 4.6 \mathrm{~mm}$ (range, $6-15 \mathrm{~mm}$ ). The total success rate including both surgical approaches was $94.4 \%$ and these results are in line with literature. Recurrence was observed in one patient and this was attributed to previous surgical operations. A conservative approach was preferred due to the small diameter of the fistula tract $(4 \mathrm{~mm})$.

Fistulas secondary to gynecological procedures are uncommon while fistulas secondary to inadequate perineal care, insufficient labor monitoring and difficulties in vaginal delivery techniques are more prevalent in Turkey. Thorough evaluation, using all diagnostic tools for complete diagnosis, understanding the pathophysiology and choosing the best surgical procedure are mandatory to obtain good outcomes after the surgical procedures.

\section{References}

1. Symmonds RE. Incontinence: vesical and urethral fistulas. Clin Obstet Gynecol 1984 Jun;27(2):499-514.

2. Önol FF, Yıldırım Ü. Genitoüriner Fistüllerde Transvajinal Onarım. Kontinans ve Nöroüroloji Bülteni 2015;2:6873.

3. Ahmed S, Holtz SA. Social and economic consequences of obstetric fistula: life changed forever? Int J Gynaecol Obstet 2007 Nov;99(1):10-15.

4. Wall LL. Obstetric vesicovaginal fistula as an international public-health problem. Lancet 2006 Sep 30;368 (9542):1201-9.

5. Langkilde NC, Pless TK, Lundbeck F, Nerstrom B. Surgical repair of vesicovaginal fistulae-a ten-year retrospective study. Scand J Urol Nephrol 1999 Apr; 33(2): 100-3.

6. Blaivas JG, Sandhu J. Urethral reconstruction after erosion of slings in women. Curr Opin Urol 2004 Nov;14 (6):335.

7. Faiena I, Koprowski C, Tunuguntla H. Female Urethral Reconstruction. J Urology 2016 Mar;195(3): 557-67.

8. Kelly J. Vezikovaginal fistula. Br J Urol 1979 Jun;51(3): 208-10.

9. Gerber GS, Schoenberg HW. Female urinary tract fistulas. J Urol 1993 Feb;149 (2):229-36.

10. Browning A. Lack of value of theMartiusgraft in obstetricfistularepair. Int J Gynaecol Obstet 2006 Apr;93(1): 337.

11. Daly JW, Higgins KA. Injury to the ureter during gynecologic surgical procedures. Surg Gynecol Obstet 1988 Jul; 167(1):19- 22.

12. Hilton P. Fistulae. In: Shaw R, Souter W, Stanton S, editors. Gynecology 2. ed. London:Livingstone, 1997;779801.

13. Nesrallah LJ, Srougi M, Gittes RF. The O'Conor tech- nique: the gold standart for supratrigonal vesicovajinal fistula repair. J Urol 1999 Feb;161(2):566-8.

14. Vangeenderhuysen C, Prual A, Ould el Joud D. Obstetric fistulae: incidence estimates for sub-Saharan Africa. Int J Gynaecol Obstet 2001 Apr;73 (1):65-6.

15. Eilber KS, Kavaler E, Rodriguez LV, Rosenblum N, Raz S. Ten-year experience with transvaginal vesicovaginal fistula repair using tissue interposition. J Urol 2003 Mar; 169(3):1033-6.

16. Lee RA, Symmonds RE, Williams TJ. Currentstatus of genito urinary fistula. Obstet Gynecol 1988 Sep;72(3): 313-9.

17. Çiftçi H, Savaş M, Altunkol A, Yeni E, Verit A, Verit FF et al. İyatrojenik Vezikovajinal Fistüller: Tedavi ve Başarıyı Etkileyen Faktörler. J Turk Soc Obstet Gynecol 2010;7:(4) 294-8.

18. Kaplan Ö, Güney M. Obstetrik ve jinekolojik operasyonlar sonrasinda gelişen vezikovajinal fistüllerin retrospektif değerlendirilmesi. S.D.Ü. Tıp Fak Derg 2014;21(3):72-7.

19. Karateke A, Asoğlu M, Selçuk S, Cam C, Tuğ N, Ozdemir A. Experience of our surgery in iatrogenic vesicovaginal fistulas. J Turk Ger Gynecol Assoc 2010 Sep 1;11(3):13740 .

20. Ou CS, Huang UC, Tsuang M, Rowbotham R. Laparoscopic repair of vesicovaginalfistula. J Laparoendosc Adv Surg Tech A 2004 Feb;14 (1):17-21.

21. Mathevet P, Valencia P, Cousin C, Mellier G, Dargent D. Operative injuries during vaginal hysterectomy. Eur J Obstet Gynecol Reprod Biol 2001 Jul; 97(1):71-5.

22. Bai SW, Huh EH, Jung da J, Park JH, Rha KH, Kim SK, et al. Urinary tract injuries during pelvic surgery; incidence rates and predisposing factors. Int Urogynecol $\mathrm{J}$ Pelvic Floor Dysfunct 2006 Jun;17(4):360- 4.

23. Harris WJ. Early complications of abdominal and vaginal hysterectomy. Obstet Gynecol Surv 1995 Nov;50(11): 795-805.

24. Ostrzenski A, Ostrzenska KM. Bladder injury during laparoscopic surgery. Obstet Gynecol Surv 1998 Mar;53 (3): $175-80$

25. Armenakas NA, Pareek G, Fracchia JA. Iatrogenic bladder perforations: long term follow up of 65 patients. J Am Coll Surg 2004 Jan;198(1):78-82.

26. Likic IS, Kadija S, Ladjevic NG, Stefanovic A, Jeremic K, Petkovic S, et al. Analysis of urologic complications after radical hysterectomy. Am J Obstet Gynecol 2008 Dec;199 (6):644 e1-3.

27. Rao MP, Dwvedi US, Datta B, Vyas N, Nandy PR, Trivedi $\mathrm{S}$, et al. Post caesarean vesicouterine fistulae-Youssef syndrome: our experience and review of published work. ANZ J Surg 2006 Apr;76(4):243-5.

28. Youssef AF. Menouria folloeing lower segment cesarean section: a syndrome. Am J Obstet Gynecol 1957 Apr; 
73(4):759-67.

29. Çiçek T, Duman E, Toprak E, Koşan M. Vesicouterina fistula:Youssef's syndrome. Gaziantep Med J 2015;21(3):221-3.

30. Goel A, Goel S, Singh BP, Sankhwar SN. Cystographic Images of Youssef Syndrome: lower on Top of Bladder. Urology 2012 May;79(5):69-70.

31. Tancer ML. Vesicouterine fistula a review. Obstet Gynecol Surv 1986 Dec;41(12):743-53.

32. Sharifi-Aghdas F, Ghaderian N, Payvand A. Free bladder mucosal autograft in the treatment of complicated vesicovaginalfistula. BJU Int 2002 Mar;89 Suppl1:54-6.

33. Kirschner CV, Yost KJ, Du H, Karshima JA, Arrowsmith SD, Wall LL. Obstetric fistula: the ECWA Evangel VVF
Center surgical experience from Jos, Nigeria. Int Urogynecol J 2010 Dec;21(12):1525-33.

34. Ahmad S, Nishtar A, Hafeez GA, Khan Z. Management of vesico-vaginal fistulas in women. Int J Gynaecol Obstet 2005 Jan;88(1):71-5.

35. Kristensen JK, Lose G. Vesico-vaginalfistulas: the transperitoneal repair revisited. Scand J Urol Nephrol 1994; 157:101-5.

36. Ersay A, Beyhan G, Yalınkaya A, Akay F. Üretrovajinal ve vezikovajinal fistüller: Onarım yöntemlerinin karşılaştırılmas1. T Ürol Derg 1999;25(3):339-45.

37. Emekçioğlu O, Kenan B, Demirci D, Yılmaz U, Tatlışen A, Gülmez İ. Yirmibir hastada vezikovajinal fistül onarım sonuçlarımız. T Ürol Derg 1999;25(1):80-3. 